\title{
Automated policing: the case of body-worn video
}

\author{
Ben Bowling ${ }^{1 *}$ and Shruti Iyer ${ }^{2}$ \\ ${ }^{1}$ Professor of Criminology and Criminal Justice, King's College London and ${ }^{2}$ Undergraduate Research Fellow, King's College \\ London \\ ${ }^{\star}$ Corresponding author. E-mail: Ben.bowling@kcl.ac.uk
}

\begin{abstract}
This paper examines the impact of body-worn video (BWV) on the police craft skills of close observation, note-taking, investigative analysis, report-writing and preparation of evidence for the courts. It explains how the technology functions and explores its surveillant, investigative, probative and regulatory applications. The evidence shows that policing tasks are being transformed by BWV cameras and analytics such as facial recognition. The paper argues that BWV exemplifies the automation of policing - the replacement of police labour with mechanical devices - and explores the implications of this for transparency, accountability, fairness and police discretion.
\end{abstract}

\section{Introduction}

According to Hartzog et al. (2015, p. 1769), '[w] e are entering a new era when large portions of the law enforcement process may be automated ... with little to no human oversight or intervention'. In this paper, we seek to explore this contention by looking specifically at the introduction of body-worn video (BWV) into policework and its implications for the automation of policing (Joh, 2018a; 2018b). The use of technological processes, unmediated by human interaction or assistance, is increasing across a range of human activities, such as robotic manufacturing and 'smart' self-monitoring infrastructure systems, as well as in services ranging from taxi-dispatch and food delivery to nursing and legal analysis (Brownsword, 2019). As these machines develop, they aid, augment, modify and replace human actions. Arendt asserts that there is a 'decisive difference' between tools and machines. ${ }^{1}$ This is 'illustrated by the apparently endless discussion of whether man should be "adjusted" to the machine or the machines should be adjusted to the "nature" of man' (Arendt, 1998, p. 147). In her view, the direction of travel - already clear by the middle of the twentieth century - was that machines would gradually replace human labour: 'Even the most refined tool remains a servant, unable to guide or to replace the hand. Even the most primitive machine guides the body's labour and eventually replaces it altogether' (Arendt, 1998, p. 147).

\footnotetext{
${ }^{1}$ Notwithstanding Arendt's assertion, the distinction between a tool and a machine is subtle. The Oxford English Dictionary defines a tool as an 'instrument of manual operation; a mechanical implement for working on something; ... usually held in and operated directly by the hand'. A machine, by contrast, is a 'complex device, consisting of a number of interrelated parts, each having a definite function, together applying, using, or generating mechanical or electrical power to perform a certain kind of work. ... Its use has been extended to devices that perform tasks which previously required human mental activity'. Arendt, in The Human Condition, points out that human beings have 'lived literally in a world of machines since the industrial revolution and the emancipation of labour replaced almost all hand tools with machines' (1998, p. 147). She refers to the way in which 'body and tool swing in the same repetitive motion' whereas, with machines, 'it is no longer the body's movement that determines the implement's movement but the machine's movement which enforces the movements of the body' (p. 146). While this distinction may be a matter of debate for some instruments, particularly with regard to the question of human adjustment, with others, the distinction is relatively clear. It is evident that the use of tools such as a baton or a whistle alter policework but in nowhere near as far-reaching a fashion as that brought about by the incorporation of a machine such as a BWV camera into the police officer's uniform.
}

(c) Cambridge University Press 2019 
In this paper, we seek to explore the impact of technology on policing - in particular the introduction of the BWV camera into the standard toolkit of front-line police constables on patrol and responding to public calls for service. We consider this shift in the context of the automation of human labour and of the specific applications of technology to law enforcement and crime control (Bowling et al., 2008). We dwell momentarily on the paradigm example of existing law-enforcement automation: road-traffic policing. In this case, machines monitor roads, identify road-traffic law violations, record evidence of wrongdoing, prove that an offence was committed and issue a penalty (Marks et al., 2017). We consider whether the introduction of BWV cameras presents similar possibilities by compressing hitherto separate elements of criminal justice - surveillance, investigation, testing evidence and judging guilt - into a single technologically mediated process.

We situate the introduction of BWV within a larger paradigm shift in policing, where technology is altering and replacing human behaviour and decision-making. Within this background shift towards automation, we examine the ways in which BWV is embedded within human action, generating new forms of policework while eliminating and transforming others. We ponder the scope for discretion currently given to officers in the decision to turn the body-worn camera on and off. Given this discretion, it is unclear whether the stated intentions of BWV use - effective, transparent and accountable policing - have been achieved. The issue of discretion is linked with further questions: What has in fact been automated, and to what degree? And what is the potential for automation to be overridden manually? Contrasting manual and automated policing also draws attention to the discriminatory outcomes associated with high levels of discretion, as well as the fear that perfectly enforced laws might erode contextualised decision-making and citizens' reasonable expectation of privacy. In this sense, BWV operates in a continuum of surveillant and investigative technologies that generate information on citizens, but it is distinct, as the automation it enables remains dependent on human intervention and interpretation. As the direction of further development is towards more advanced automation, we conclude with a series of general remarks to do with this shift in policing and the questions that it raises for scholars, legislators and the wider public.

\section{Conceptualising automated policing}

The police have used tools in their work since the birth of their profession. The first police constables were issued with a toolkit comprising a weapon (a truncheon), means of restraining suspects (handcuffs), devices for communication (a whistle) and record-keeping (pocketbook, pen, paper files and card index). As policing developed during the nineteenth and twentieth centuries, police organisations incorporated new technologies - 'scientific knowledge, materials, techniques, systems, methods or organisation and the use of electronic and mechanical devices' - into their operational practice (Bowling et al., 2008, p. 51). The tendency is for manual tools to be replaced by mechanical devices, including new weapons (friction lock extendable baton, pepper spray), new means of restraint (electronic stun guns), new means of communication (two-way radios, mobile phones) and new methods of record-keeping (computers, databases, audio and video recording). The criminal justice system has been used as a testing ground for technologies used extensively in unrelated fields, including science, engineering, medicine and commerce.

A century and a half ago, Karl Marx argued that 'crime, through its constantly new methods of attack on property, constantly calls into being new methods of defence, and so is as productive as strikes for the invention of machines' (1863/1978, pp. 378-388). Included among what Marx describes as the 'most ingenious mechanical inventions' developed to defend property against crime are the applications of chemistry, engineering, optical lens manufacturing and engraving (Marx, 1863/1978, pp. 378-388). Marx asked whether locks, banknotes, microscopes and chemical analysis would have 'reached their present degree of excellence' had there been no thieves, forgers, fraudsters and adulterators. The same question could today be asked about DNA analysis, ion-scanning, facial recognition and many other inventions used widely in science and society whose development was spurred on by their value to crime control. 
In a prescient analysis of workplace automation, Zuboff (1988) identified a distinguishing feature of information technology. While used to 'reproduce, extend and improve upon' human labour, the mechanical devices that automate 'also register data about those automated activities, thus creating new streams of information' (Zuboff, 1988, p. 9). Information technology not only automates action in ways that increase certainty, precision, continuity and control, but it 'symbolically renders events, objects, and processes so that they become visible, knowable and shareable in a new way' (Zuboff, 1988, p. 9). To capture the way in which information technology 'supersedes the traditional logic of automation', Zuboff coined the word informate to describe the translation of activities, events and objects into visible information (Zuboff, 1988, p. 10). For Zuboff, 'informating derives from and builds upon automation' and, while the former is experienced as an unintended consequence of the latter, managers can exploit, sustain and develop emerging informating capacity. This insight led Zuboff (2013) to set out three 'laws' of information technology: (1) Everything that can be automated will be automated; (2) Everything that can be informated will be informated; and (3) In the absence of countervailing restrictions and sanctions, every digital application that can be used for surveillance and control will be used for surveillance and control, irrespective of its originating intention. This view chimes with Hartzog et al. (2015), who argue that, 'once adopted, automated systems become entrenched and difficult to modify' (p. 1763). Therefore:

'the initial design and implementation of automated law enforcement systems must preserve an adequate amount of indeterminacy and inefficiency. Given the effect automated law enforcement systems can have on our core interests of freedom, autonomy, due process, and privacy, there is simply too much at stake to place cost and efficiency above all other concerns.' (Hartzog et al., 2015, p. 1763)

Our general interest is seeking to understand how new technologies are changing the nature of policework (Bowling et al., 2008). The term 'policework' encompasses the everyday tasks carried out by police officers, including patrolling, responding to calls for service, maintaining order, investigating allegations of crime and preparing cases for prosecution (Bowling et al., 2019). There are, however, specific aspects of the police occupational environment - its métier - that make it a unique form of labour (Bowling et al., 2019). Policework is best defined not by the myriad tasks police carry out, but by its core powers, which are the capacity to use coercive force and intrusive surveillance, and the ways these are used to maintain order (Bowling et al., 2019). Policework has two other properties that make it an unusual form of governmental labour. First, discretion in decisionmaking tends to be widest at the lowest level of the organisation. The police constable has broad latitude to decide which laws to enforce, against whom and how. Second, policework has been thought of as a 'low-visibility' activity because it is carried out on the streets at a distance from supervisors and often involves interaction with powerless social groups (Goldstein, 1960).

The application of new mechanical and electronic devices to policing has a double edge: it contributes to expanding and enabling police powers but, in the process of informating, it also has the potential to increase visibility and reduce discretion. New technologies automate and change the shape of the craft skills of policing, but also informate the practice of policework. The rapid increase in audio-visual, geo-coded, statistical and other data has given rise to what some police researchers refer to as the 'new visibility' of policing (Goldsmith, 2010; Brown, 2016; Sandhu, 2016). Here, we restrict ourselves largely to work carried out by the public police, not by private security, though many relevant tasks may also regularly be carried out by private security forces (Bowling et al., 2019).

Drawing on the Oxford English Dictionary for help, we define automated policing as policework that has been converted so as to operate automatically. There are three nuances to the idea of automation that are relevant in this context. First, and most importantly, it refers to the use of a mechanical device to replace human labour that can function with little to no direct control from a human being. In our example, a body-worn machine camera system that can collect and store visual and aural information replaces the manual craft skills of close ocular observation, vigilance, attentiveness, detecting 
significant events, note-taking, record-keeping, issuing notices and alerts, and preparing reports. In this instance, the machine has capabilities that exceed those of a human being and has the capacity to replace police labour entirely. In a sense, because the police officer who is physically present is still engaging in observation and detection, the machine also augments their capacity for recall and investigation. A second nuance is that something accomplished automatically is done without requiring conscious thought or attention. A video camera, once recording has started, continues until it is switched off or the battery runs out. Surveillance cameras record everything automatically in this sense. A third nuance stems from how technology contributes to the growth of 'summary justice' processes in which punishment is imposed as a necessary and inevitable result of a fixed rule or particular circumstances (Jackson, 2008; Marks et al., 2017). An example of this would be the automatic issuing of fixed penalties for specific driving offences, such as speeding or running a red light. Other forms include automatic reprimands and warnings for young offenders, fixed penalties for drug possession or public disorder, and strengthening incentives to plead guilty early in the criminal justice process (Marks et al., 2017, p. 710; Jackson, 2008). In this sense, automation goes beyond data collection and evidence testing to include the imposition of punishment itself.

Bowling et al. (2008) argue that it is helpful to consider the applications of specific technologies to different aspects of crime control, focusing attention on the use of scientific knowledge and technology in a variety of everyday activities and tasks (p. 54). The applications relevant to BWV are surveillant, investigative, probative and regulatory ${ }^{2}$ :

- Surveillant applications focus on detailed observation of people, places, events and the recording of those observations.

- Investigative applications focus on collection and analysis of information relating to offences and offenders including records, observational data, suspects and witness interviews and physical evidence.

- Probative applications focus on examination and assessment of evidence in order to determine guilt or innocence.

- Regulatory applications seek to regulate policework by making it more transparent, lawful and accountable.

The same mechanical devices can be used for these four very different purposes. For example, the camera used to carry out general surveillance of a public place can also be used to record an interview with a witness, identify a suspect or present evidence of wrongdoing in court. It can identify whether or not a police officer has acted appropriately in an encounter with a member of the public, in disciplinary action against the officer and it can be used for the purpose of training.

The clearest example of automation in policing can be found in road policing and traffic law enforcement. This was first noted by Jerome Skolnick (2011) in his classic monograph, Justice Without Trial. This includes a perceptive analysis of the automated processing of traffic tickets, which clearly illustrates automation in the administration of criminal law. Over time, technologies have been introduced that make it possible to carry out traffic enforcement of parking and speeding offences with little or no human assistance (Wells, 2008). The detection and punishment of speed-limit violations (itself a response to the rapid development of motor-vehicle technology) was initially a manual process known as a 'speed trap'. This required the craft skills of observing vehicles,

\footnotetext{
${ }^{2}$ This departs from Hartzog et al. (2015), who argue that the three major components of automated law enforcement are (1) surveillance, (2) analysis (resulting in a determination of guilt or innocence) and (3) action (resulting in punishment or freedom). There are three problems with Hartzog's typology. First, it misses the investigative role, which does include the analysis of surveillance data, but also includes interviewing, collection of documents and physical evidence. Second, analysis does not in itself result in a determination of guilt or innocence, but simply puts forward evidence on which a determination of guilt (what we call the probative role) can be made. Analysis of the evidence is of course important, but testing the evidence also requires judgment - as a procedural moment as well as a personal quality. Third, the 'actions' of the police are quite limited and are not captured in the idea that they can produce the results of punishment or freedom.
} 
writing down registration numbers with pen and paper, and using a manual stopwatch to calculate the average speed between two previously measured fixed points. The information was collated, analysed and used as the basis for prosecution, which usually required a court appearance before a judge or magistrate to reach a verdict and impose financial and other penalties.

The technology that is widely used today enables cameras to read vehicle licence plates automatically, photograph the driver's face and accurately measure the vehicle's speed. Traffic-enforcement camera systems connect seamlessly to criminal and licencing databases and to the courts, which issue fixed penalties. As well as conducting speeding enforcement, UK police forces seize about 500 vehicles per day on suspicion of being driven without insurance (McGarry, 2011, p. 220; Motor Insurers' Bureau, 2010). This is the result of both routine police checks and 'crackdown' operations. The process uses Automatic Number Plate Recognition (ANPR) to cross-check vehicles against the Police National Computer, which is linked to the Motor Insurance Database and the Driver and Vehicle Licensing Agency, automatically cross-checking licence and insurance records (Kinsella and McGarry, 2011). Skolnick also refers to traffic policing as an example of the mass production of penalties. These have been imposed automatically for many years, in the sense of being issued as a necessary imposition of a fixed rule, but have increased dramatically in the past half-century. Fewer than 17,000 automatic penalties were issued in the UK in 1960; in 2011, this number had grown to 10 million (Snow, 2017).

Automation changes the character of the administration of justice because the hitherto separate processes of observation, evidence collection, adjudication and punishment can be collapsed into a single process (Marks et al., 2017). Of course, a great deal of labour is still required to manage this system, but it is of a radically different, mechanically mediated, kind. 'With a high degree of automation, the offence is surveilled, investigated, detected, and proven and the "offender" punished, named, and shamed' (Marks et al., 2017, p. 715). Now that mechanical devices speak directly to each other through computer networks - creating the so-called 'Internet of things' - 'it is possible to imagine a world in which citizens are investigated, evidence collected against them, a judgment of guilt reached, and a penalty issued without the participation of a human being at any stage' (Marks et al., 2017, p. 715).

How far is it possible to anticipate the automation of ordinary street policing? The vision of police leaders, such as former Commissioner of the Metropolitan Police Lord Bernard Hogan-Howe, is towards a 'truly digital police force' that will 'use digital to connect the criminal justice system from the very first report of a crime through to a court appearance, an end-to-end service'. This, according to Lord Hogan-Howe, will reap 'the benefits of digital technology and smarter ways of working', including an improvement in quality of service, productivity, efficiency and effectiveness (Hogan-Howe, 2015, p. 15, cited in Marks et al., 2017). This paper explores the role of the body-worn camera in this vision and the part it may play in the development of automated policing.

\section{Understanding BWV technology and its applications in policing}

BWV devices were first piloted in the UK in 2005 and are now widely used by police officers across England, Wales, Scotland and Northern Ireland. Not all officers are issued with cameras, but the intention is for all front-line officers responding to calls for service, on routine patrol, tactical support, roads policing and armed response units to be equipped with BWV. The technology is also widely used in many other parts of the world and is increasingly seen as a normal part of the police uniform. The Home Office estimated that the number of BWV cameras in the UK had reached 60,000 by the end of 2017 (Home Office, 2017b). Most devices used in the UK are made by Axon, formerly Taser International, but worldwide there are more than sixty products produced by at least thirty-eight manufacturers (Hung et al., 2016). Market analysts estimate that there are 1.5 million devices in use worldwide and predict that the market will grow from $\$ 260$ million in 2017 to between $\$ 990$ million and $\$ 1,800$ million by 2023 .

The Axon Body 2 device is a small front-facing camera within a tamperproof hard casing worn on the front of the uniform. These cameras record in high definition in low light with audio that has 
automatic tuning and noise reduction. The camera is capable of recording up to 70 hours and can use Wi-Fi to stream videos and Bluetooth to assign meta-data. On its front panel - facing the viewer - the camera has a yellow label with a camera icon and the words 'video and audio'. It has a light at the top to show the user when recording is on and a flashing red light at the front for the public to see; it emits an electronic beeping sound every 30 seconds. London Metropolitan Police Service (MPS) policy is that, unless circumstances prevent it, officers are required to make a verbal statement when they switch on the camera. The continuous non-specific use of BWV is explicitly prohibited in UK policy documents; its usage should be 'incident-specific', proportionate and necessary to the situation (House of Commons, 2015; Metropolitan Police, 2016; Home Office, 2017a).

The MPS policy is prefaced with the principle that BWV is useful for recording evidence in respect of suspected offences and demonstrating transparency in respect of police actions at incidents, in situations when the officer would have been 'expected or required to have completed a written record or report on an encounter or incident' or where recording may be of future evidential value and the making of a recording is proportionate and lawful in the circumstances. The policy states that it should be used to record evidence of an offence, in stop-and-search in public places, searches of premises, use of force or making an arrest, when attending domestic-violence situations and numerous other situational exigencies (Metropolitan Police, 2016).

Videos cannot be reviewed while officers are still on patrol and must be uploaded securely to be viewed. They are time- and date-stamped, and the claim is that encrypted files cannot be deleted, corrupted or viewed without the requisite software. 'Back-end' infrastructure supports the use of the devices: specialised software onto which the camera uploads footage when connected to a docking station and computers that are connected to external hard drives or cloud storage onto which the data are uploaded (Tubb, 2015; Peachey, 2016). However, many BWV systems allow cameras to be turned on and off remotely and for feeds to be monitored back at the station (Pasternack, 2017a). This has serious consequences for the security of the data, even if the current technology does not allow highly accurate labelling or recognition.

In the US, BWV is used to 'create a continuous feed of the people police come in contact with during daily routines' (Ferguson, 2017, p. 89). This, notwithstanding limits of battery life and digital storage space, is clearly an option in the UK. Numerous experiments with static cameras have shown that it is possible to scan live video from a distance of up to 200 metres and, using a biometric algorithm that analyses facial features quantitatively, match faces with those held on police databases (Ferguson, 2017 , p. 89). The next generation of BWV enables real-time facial recognition. This can be used to identify where and when the police make contact with a particular person and will give police access to their criminal records, active warrants and other information. Facial-recognition technology is developing rapidly. Facebook's programme 'DeepFace' claims a 97 percent accuracy rate across its platforms (Ferguson, 2017, p. 89). Face recognition is also used extensively in automated border-control systems at airports and has been experimented with at music festivals and sporting events. The technology is also soon to be trialled as the basis for a payment system on the London Underground. Use of live video is not as straightforward as static photographs because of the effects of lighting, movement and camera angles. However, once technical limitations on picture quality, camera storage capacity and battery life are overcome, the use of BWV for real-time facial recognition - sometimes referred to as face-printing - will become as unremarkable as fingerprinting and far more ubiquitous.

\subsection{Surveillant applications}

The goal of surveillance, a key element of the police métier, is to keep watch over individuals and groups of people. Surveillance can be targeted at specific individuals or to observe masses moving through public spaces. Technological devices have extended powers beyond human visual capacity to include infra-red night vision and can incorporate sensitive listening devices and chemical sensors. Smart surveillance devices are able to recognise faces, extract information from documents and read vehicle number plates. BWV collects information once the officer is on the scene and is currently used 
mostly as a focused tool rather than a mode of general surveillance. ${ }^{3}$ It can, of course, also be used for general overt surveillance (much like static CCTV) and covert surveillance, though this is prohibited in the UK except in 'exceptional circumstances' and where the 'necessary authorities have been granted' (Metropolitan Police, 2016). In what Marx (2002) calls 'new surveillance', technology is used to extract or create personal or group data, obtaining more information about citizens than would be available from a traditional search or questioning. But BWV here operates to obtain not simply more information, but more enduring information that can be used in later stages of the criminal justice system. The Metropolitan Police states that data from the cameras are automatically uploaded to a secure server and deleted after 30 days unless required as evidence in an investigation or a complaint against an officer. ${ }^{4}$ However, if the data are deemed relevant evidence, they could be stored indefinitely (Magee, 2016).

As Adams and Mastracci (2017) point out, while BWV purports to surveil police officers, the frame of its view is pointed outwards: to subjects interacting with the officer and victims of crime. The surveillant scope of the BWV camera presents 'particularised dangers to victims because of the boundaries they are able to cross ... [BWVs] bring state surveillance into homes and private spaces, often during what is already the most horrific, vulnerable point in someone's life' (Adams and Mastracci, 2017, p. 324). BWV can also be shared between criminal justice agencies, analysed using face- or voice-recognition technologies and cross-referenced with other information. Given that the faces of half the US adult population are already in searchable federal, state or local databases (Pasternack, 2017a), body cameras offer unprecedented capacity for intelligence-gathering, which has far-reaching implications.

\subsection{Investigative applications}

Crime investigation involves the collection and analysis of evidence for the purpose of fact-finding and identifying suspects in specific crimes and in 'proactive investigation' of crimes in prospect (Bowling et al., 2008, p. 56). BWV can record events at the scene of an incident and interactions between officers and others present; record interviews and statements from suspects and witnesses at the scene; store and analyse information on offences committed; and secure evidence to prosecute or eliminate a suspect from an inquiry. The role of BWV as an investigative tool seems set to grow as algorithms become more adept at sifting through video footage for indexing, searching and triage. The information collected can be categorised by the type of activity or encounter and this can be done spatially, alongside other technologies, to predict crime hotspots (Sanders and Sheptycki, 2017). Linking BWV footage to face and voice recognition expands the capacity for it to be used to identify suspects. In Seattle, Chicago and Leicestershire in the UK, the police have analysed recorded visual data with facial-

\footnotetext{
${ }^{3}$ This distinguishes BWV from forms of generalised surveillance such as static closed-circuit television (CCTV). BWV is distinct first in its physical attachment onto the police uniform and therefore presence on the human body. This integration of the machine into the police officer and his or her daily practice brings with it a capacity to capture moving images and sound routinely, including targeted footage of individuals on the streets and within the hitherto private spaces of their homes. The penetration of BWV is thus far greater than static CCTV cameras and its evidentiary usage is far more directed. Many of the concerns that we highlight in this paper, particularly to do with the wide array of applications of surveillance technology to policework, discriminatory outcomes, the question of effective legal regulation and detrimental privacy outcomes apply equally to CCTV surveillance cameras. See Taylor and Gill (2014); Edwards (2005); Goold (2002; 2004); Stedmon (2011); Norris and Armstrong (1999). A sustained exploration of the similarities and differences between BWV and CCTV in policework is beyond the scope of this paper, but is a necessary area of further research and could inform an understanding of how diverse surveillance tools operate in tandem to produce criminal justice outcomes.

${ }^{4} \mathrm{BWV}$ footage is retained in accordance with the Data Protection Act 1988 (now 2018). Unless it is marked for retention as evidential footage, the claim is that the system auto-deletes it after thirty days. The College of Policing guidelines also state that the thirty-day period may be too long and forces may have to develop a justification as to why it is not practicable to delete footage in a shorter time period (2014, p. 15). The Surrey Police BWV procedure (2017) states that the following types of footage are evidential footage: (1) evidence of an offence; (2) supporting evidence for any process (e.g. charge, fixed penalty notice, penalty notice for disorder, etc.); (3) footage that helps the police to defend civil claims made against them; (4) footage required for a relevant and proportional policing purpose; or (5) footage disclosable under the Criminal Procedure and Investigation Act 1996.
} 
recognition software (Adams and Mastracci, 2017, p. 321; see also BBC News, 2014; RT News, 2013; Sanburn and Sifferlin, 2014). Facial-recognition software has also already been paired and rolled out with dash-cams, allowing real-time recognition (PRNewsWire, 2017).

Taser have trialled facial recognition on BWV data since 2009 and recently acquired Dextro, a company with artificial-intelligence (AI) software capacities that can tag and flag footage and redact sensitive information prior to disclosure (Pasternack, 2017b). Aguayo et al. (2017) devised an algorithm, based on a sample of LAPD videos and additional simulation videos, that uses BWV data to identify foot chases. Their algorithm has achieved a high success rate. Allen et al. (2017) use 'change-point detection' algorithms to identify video segments where an officer speaks or interacts with a person, movement into or out of vehicles and buildings, handcuffs someone or is engaged in a foot chase. The purpose of these is to generate automated labelling mechanisms, allowing the police to more easily search through a vast database of recorded videos to find specific interactions. AI can also be used for automated report-writing or to produce written cues for officers writing reports to 'jog their memory' (to which we return below). AI can also read BWV data to identify and automatically extract details from ID cards and vehicle licence plates.

The investigative potential of this technology goes far beyond evidence collection, moving into the realm of evidence sorting, with direct probative consequences. However, at present, the scope of the existing technology is limited: it is very difficult to accurately use facial recognition on BWV footage because of the field of view, constant movement (particularly of those in vehicles) and potential lighting issues. It seems clear that the direction is towards higher accuracy and equipment improvement; in 2016, nine of thirty-eight BWV manufacturers included facial-recognition systems or were working towards future inclusion (Hung et al., 2016).

\subsection{Probative applications}

Probative applications are those that have the function of testing evidence or establishing proof of alleged facts. BWV evidence can be collated for the purpose of framing criminal charges and proceedings through which guilt or innocence can be proven. In some instances, video footage can be taken as compelling evidence of wrongdoing or even conclusive proof. BWV represents a technological change that digitises and visually depicts the analysis of evidence from those suspected of crime, or witnesses to it, at the scene. This video can be used as evidence in prosecution and sentencing.

In 2016, the Independent Police Complaints Commission (IPCC) cautioned that undue weight may be attached to the evidential value of BWV footage even though it cannot capture the atmosphere of a situation, events that occurred prior to it being turned on or what might be happening behind the lens. It states:

' $\mathrm{t}$ ] here is a risk that other important evidence could be ignored or given less value. At worst, the footage could present a positively misleading picture of the whole situation. From a complaints handling and investigation perspective, initial written accounts are useful because they have the potential to record much more detail, including the officer's perception of the event and how that informed their actions. This information can be pivotal in assessing whether an action was reasonable. If officers routinely view BWV footage before giving their initial written account there is a risk that statements present merely a commentary on the footage rather than the officer's own perceptions and thought processes. Additionally, there is a risk that watching $B W V$ footage may affect an officer's recollections of an event.' (IPCC, 2016, p. 2, emphasis added)

This is important, because it is unclear whether officers are given adequate training in integrating the technology into their work in a way that does not damage the quality of evidence generated by BWV. The College of Policing guidelines are clear that BWV must operate in tandem with manual notetaking and is not intended to replace it. However, it is highly plausible that note-taking and reportwriting to record incidents on patrol or witness statements will eventually be made redundant by 
BWV footage (Hymas, 2018). A Computing Community Consortium White Paper (Corso et al., 2015) recommended that automated video summarisation using indexing algorithms should be created for all videos to improve officers' memory of events. This would certainly supersede note-taking rather than being supplementary or complementary to it. Automated report-writing based on footage is now technically possible and would mark a shift in policework similar to the introduction of tape recording in police interviews and the introduction of evidence thirty years ago (see Willis, 1984). Efficiency is a key justification for the introduction of BWV technology. A UK Home Office study reported a 22 percent reduction in the time devoted to paperwork and case preparation due to evidence collected from BWV (Goodall, 2007).

Video recordings are now used extensively as evidence in the legal system, particularly due to the proliferation of recording devices in mobile phones, body-worn devices, CCTV, satellites, drones and dashboard cameras. However, the meaning of this visual evidence is rarely derivable on its own and it is often interpreted in conjunction with testimony and other reports. Gates (2016) notes that BWV could also be a reaction to what the police perceive as the 'uncontrolled visibility' created by the prevalence of smartphone cameras and social media, allowing them to take back control. This is sometimes termed 'camera view bias', where looking at a video filmed from a certain perspective can cause the viewer to adopt an interpretation favouring that vision (Williams et al., 2016). There is, of course, the potential to record from a different vantage point: that of the watching citizen. Officers have often been reluctant to be photographed on the job, fearing that their actions may be misinterpreted, and have sometimes been reported to engage in 'camera-friendly policing' when being watched, altering their presentation and body language to make footage more favourable (see Sandhu, 2016). It is unclear whether citizens who are filmed by the police alter their behaviour in similar ways.

There is some evidence that BWV can improve prosecution outcomes in domestic-violence cases by providing evidence from the first police response (Palmer, 2016, p. 141). A randomised control trial in Essex found that BWV increased the proportion of domestic-abuse incidents that resulted in a criminal charge but had no impact on guilty pleas or conviction rates (Owens et al., 2014). A study in Arizona concluded that BWV in domestic-violence cases was more likely to result in a guilty plea or verdict (Katz et al., 2014). However, the presence of evidence does not always make a difference; where victims retracted their statements or did not support prosecution, the evidence did not prevent cases from ending in no further action. Palmer (2016) found that the benefits of enhancing prosecutorial outcomes is mixed: public-order offences have a generally high degree of prosecutorial success because there is a filtering of offences before they reach trial. BWV is unlikely to have a significant impact on family violence, sexual assault and other assaults, however, because the police are generally not there to record the act itself (Palmer, 2016, p. 142). The claim is that recordings as evidence will improve convictions because the victim will not have to give testimony in court.

In late 2017, the Home Office tabled plans for using BWV in interviews with suspects away from the police station (Home Office, 2017b). The justification for this was to increase the time spent on the front line, minimising the time spent in trips to and from the police station. This marked a shift in both the location of interviews and the modes by which evidence was collected. Adams and Mastracci (2017) warn that recording statements made by victims of sexual offences can have a detrimental effect when front-line officers are not trained in appropriate victim-interviewing techniques. An interview conducted in a chaotic and difficult setting can memorialise on video evidence that could harm the complainant's case and cause further victimisation in court (Adams and Mastracci, 2017).

There are also concerns that footage may be used to coerce plea bargains, even where the evidence is not definitive (Mateescu et al., 2016). None of these concerns is unique to BWV, but this technology collects information on all surrounding activity in the field of the police officer, capturing everyday interactions and any sound within its range. This makes the field of interpretation much larger than a photograph or even a static surveillance camera. A 2014 review found that early guilty pleas were obtained in 91 percent of cases where camera footage formed part of the evidence and the BBC said this allowed ' 697 officers to be on the streets rather than in the courts' (Ellison and Adams, 2017). Grampian Police guidelines note that 'BWV evidence has negated the need for a high number of Officers to attend Court as 
Police witnesses and has also reduced the demand on Officers to provide statements for court purposes' (Police Scotland, 2015, p. 4). This framing is telling, particularly in respect of how BWV automates probative functions of the police: it prioritises a vision of policework where the police are on the streets 'tackling crime' and disparages work done in the courts to ensure a fair trial as inefficient use of resources. In other words, the work of the police off the streets is a secondary function, to be done away with and automated if possible. This points to a significant change in the nature of everyday policework. Technology is seen as an obvious and effective solution to the collection and analysis of evidence, even though its real-world effects and impact on behaviour are unknown.

Hartzog et al. (2015, p. 1788) warn that 'automation bias' - the 'human tendency to irrationally trust automated decisions'- is likely to grow, with serious consequences for how BWV footage is interpreted in the courtroom. As a result, it becomes all the more important to understand the extent to which and how BWV footage is used in criminal trials (such as how often it results in convictions and guilty pleas) and on the types of charge in which guilty pleas or convictions are most likely to occur. While there are protocols on how camera footage is to be uploaded and stored, no records seem to be kept of how BWV footage is used in trials (Big Brother Watch, 2017). If this is the case, there is no empirical way to test claims that technology will improve either the administration of justice or sentencing.

\subsection{Regulatory applications}

Regulatory applications are those that seek to make police conduct transparent, to regulate and hold the police accountable for their actions. Civil-society and government organisations assert that BWV will hold the police better to account in cases of police misconduct or fatal shootings by providing a full account of what transpired in each incident and building community confidence in the police. BWV, in this view, has the potential to change the behaviour of the police and the people that they interact with, and affect criminal justice outcomes. The American Civil Liberties Union (ACLU), for example, say that, although they take a 'dim view' of the proliferation of surveillance cameras, BWV is different because of its:

'potential to serve as a check against the abuse of power by police officers. Historically, there was no documentary evidence of most encounters between police officers and the public, and due to the volatile nature of those encounters, this often resulted in radically divergent accounts of incidents. Cameras have the potential to be a win-win, helping protect the public against police misconduct, and at the same time helping protect police against false accusations of abuse. We're against pervasive government surveillance, but when cameras primarily serve the function of allowing public monitoring of the government instead of the other way around, we generally support their use. ${ }^{5}$ (Stanley, 2015)

In the aftermath of the shooting of Michael Brown in Ferguson, Missouri, more than 140,000 people signed a White House petition in favour of creating a 'Mike Brown Law' that would require the police to wear body cameras. The Obama administration had offered partial federal funding for police departments that wanted to buy the technology (United States Department of Justice, 2015) and Taser, a leading manufacturer of the cameras, have called them a 'community transparency tool' (Li, 2014). The Metropolitan Police themselves rolled out head-mounted cameras in 2017, claiming that this was part of an effort to boost transparency (The Telegraph, 2017).

A key argument made by civil-society organisations and activists in favour of BWV is its potential to regulate police conduct, collect evidence on misconduct, deal with internal complaints and improve public image. Corso et al. (2015) argue that BWV footage could function as an early warning system, capturing data on officers who repeatedly use force or do so prematurely rather than relying on

\footnotetext{
${ }^{5}$ This view that BWV primarily serves as a regulatory tool, to check police-officer behaviour, may explain the different view that the ACLU takes on the question of CCTV, where they oppose the impulse to blanket our public spaces and streets with video surveillance' (American Civil Liberties Union, 2002).
} 
officers' self-reports of use of force. Body-worn cameras that self-activate when officers are running, raise their weapons or open car doors have been proposed; but these also assume that officer misconduct only happens in these narrowly defined scenarios (Mateescu et al., 2016, p. 125). Other potential regulatory uses of the footage are in training materials for new officers, to give them a sense of street situations (Mateescu et al., 2016, p. 125). Additionally, footage can be given out to private individuals or companies in order to train machine-learning algorithms and it is unclear what regulations apply to distributing BWV in this way.

Another push for the technology comes from the belief within police departments that the use of BWV will result in fewer complaints against officers, and therefore less money will paid out in civil lawsuits. ${ }^{6}$ The influential Rialto randomised control trial (Ariel et al., 2016) found that BWV brought about a 93 percent drop in the numbers of complaints filed against officers when they used BWVs and a 50 percent reduction in the use of force (Ariel et al., 2014; 2016; Ariel, 2016). However, a similar study by the same researcher also found that, where officers could choose when to turn cameras on and off, the use-of-force rates were 71 percent higher (Ariel, 2016). In one qualitative study, it was found to reduce the scope for unlawful stop-and-searches: 'As an officer searches one male associated with organised crime, the man points at the camera: "This [BWC] has ruined it for you, hasn't it?"' (Rowe et al., 2017, p. 87). However, a Home Office-funded trial found that the devices had no impact on the number or type of stop-and-searches conducted, on the proportion of arrests for violent crimes and 'no evidence that cameras changed the ways officers dealt with either victims or suspects' (Grossmith et al., 2015). This study did, however, find a reduced number of allegations against officers, particularly in relation to interactions with the public (Grossmith et al., 2015).

The evidence of behavioural change is, so far, mixed. In a study conducted on a larger police force, complaints (generally of misconduct) against officers increased and use of force rose by 17 percent (see Ariel, 2016). The evidence on the use of BWV varies to a great extent on the sample size and methodology used, which often makes it difficult to compare the outcomes of one study against another. For example, the Rialto trial monitored the response of the police in all activities, while the study in Denver only looked at call-to-response cases (not including instances of police-initiated contact). These discrepancies, along with those of place and circumstance, make it very difficult to arrive at a conclusive understanding of how the use of BWV affects police behaviour.

Officer perceptions of BWV are also mixed: in some trials, officers have expressed discomfort with what they see as intrusive surveillance measures that erode their discretion, introduce enhanced liability for reflexive decisions made on the job and are indicative of a mistrust of officers by the public and by management (see Ariel, 2016, pp. 752-753). However, other studies have shown that police perceptions of BWV changed over time as officers reported growing familiarity with the technology and an appreciation for its benefits (Katz et al., 2014). A survey of law-enforcement command staff found that staff with less experience tended to be more sceptical than more experienced officers of the potential for BWV to make officers and communities safer, though both younger and older officers appreciated its benefits (Smykla et al., 2015). Other surveys found that a majority of officers are comfortable with the technology.

\section{BWV and automated policing}

\subsection{Changing, not eliminating, the craft skills of policing}

The introduction of BWV in everyday policing points to broader changes in the world of work and in the production of information. Workplaces are being transformed by the introduction of new forms of

\footnotetext{
${ }^{6}$ There is some evidence to support this claim; e.g. Goodison et al. (2018) found a correlation between the introduction of BWV cameras and lower amounts paid out in civil lawsuits in Mesa, AZ and Phoenix, AZ. However, the evidence that the number of complaints made against officers in general decline is mixed: in Mesa, for example, the overall number of lawsuits increased even though the amount paid out dropped. Other studies also indicate that, in larger police forces, the number of complaints may actually rise; in a study conducted on a police force in Denver, complaints rose by 38 percent, usually for cases of misconduct and not in use-of-force cases (Ariel, 2016).
} 
technology, whether that is used to monitor workers and their efficiency or to monitor the work process itself. When considering the growth of automated policing, where policing skills are converted so as to operate automatically and are replaced by the introduction of technology, BWV exemplifies a case where the process is informated by the generation, use and interpretation of footage.

As Zuboff notes,

'as work becomes more computer-mediated, it also becomes more abstract and remote from physical cues. Learning what information might mean when it is separated from its action context requires a new emphasis on abstract thinking and relies on the ability to make explicit the inferences that link data to the concrete world.' (Zuboff, 2001, p. 11)

Gates (2016) argues that BWV heralds the growth of a 'police media economy', where the practice of policing now encompasses cultural media work that invests recordings and images with meaning. BWV functions as a way for officers to 'create representations of their encounters on the job, selfrepresentations of their subjective experiences' (p. 3). It also creates forms of work 'to process, archive, search, circulate, and render authoritative interpretations of video generated by body-worn cameras' (Gates, 2016, p. 3). Joh (2018a) argues that deskilling is a major outcome of automating policework. However, once the labour that is undertaken in categorising, uploading, sorting and analysing video evidence is considered, BWV perhaps indicates a qualitative shift towards re-skilling rather than eliminating labour by creating new kinds of scalable, infrastructural labour (Gates, 2016, p. 3). The roll-out of BWV has required a great deal of labour to navigate technical and implementation problems (see Ellison and Adams, 2017); while BWV can cut some costs, it requires continual work and investment to remain operational.

James Rule's (1973) study of the introduction of radio into police cars is instructive as an earlier example of how the introduction of technology transformed the communicative capacities of the police. For example, it increased officers' available patrol time by reducing the need to stop at phonebooths to make background-check calls. However, radio did not eliminate the time and energy involved in police communications. As Magnet and Gates note, Rule's account provides an important reference point for 'understanding transformations in police surveillance practices, especially the translation of human labour into automated, technical systems' (2013, p. 5). Police officers have witnessed many changes to evidence collection in recent decades, each of which led to a corresponding change in officer practice. The police have moved from burning DVDs by the thousand to storing video on laptops and external drives. This has become an overtime issue in some instances because officers 'worked beyond their standard working hours to try to manage video' (Gates, 2016, p. 16). If we think about the applications for which a technology is used and consider more carefully how human labour interacts or intervenes in processes, it is clear that automation is happening as part of a broader complex of human interaction, interpretation and decision-making. In the case of BWV, machines are replacing police manual labour with more powerful sensory capacities than human beings. The machines never tire and have infinitely greater memory, search, data-processing, data-linking and analytical capacities. In other instances, to paraphrase Arendt, machines are guiding the hands of the police, transforming the nature of policework such that human beings and machines work together seamlessly.

Zuboff s (1988) analysis, based on close observation of the introduction of technology in factories and offices in the 1980s, makes an important observation about the ways in which people resist the controlling functions of technology. Even where mechanisms are designed to protect workers such as automatic closing doors installed in a factory to exclude toxic gases - people find ways of disabling, disrupting and co-opting mechanical devices. The aversion to automation in the workplace seems particularly acute in policework; Khan (2015) describes it as 'rampant technophobia' at all levels of policing. Its features are resistance to automation, criticism of and opposition to technological changes, unwillingness to learn to use devices and resistance to training. Historically, this has manifested itself in the sabotage of equipment: for example, in Chicago, it was found that 80 percent of 
dashboard-mounted videos did not record audio due to 'officer error' and 'intentional destruction' (Balko, 2016). Khan explains that police technophobia is caused by an action-oriented police culture; officers feel their discretion is being eroded and that technology places the police 'under a microscope' that will test their performance and hold them to account. There is also concern about civilianisation and the creation of new hierarchies. Despite a generally technophobic culture, however, it seems clear that BWV technology is advancing rapidly through police organisations; it already seems to be widely accepted by front-line police officers.

\subsection{Manual vs. automated policing: automation, discretion and decision-making}

It may be useful to contrast manual and automated policing. Manual policework involves the use of the physical body (hands, ears, eyes and brain) to observe, record and make sense of the world. Police generally have wide discretion in the use of these physical capacities and craft skills. Human volition lies at the heart of the process and officers are allowed to make their own judgment in procedures and decision-making. Manual processes have the virtue of human judgment and adaptability, and yield appropriate emotional responses such as attentiveness, sympathy and kindness. The downside is that manual policing is susceptible to error; unpredictable and inconsistent actions; inappropriate emotions such as anger, frustration, disgust and contempt; and provides scope for prejudiced and discriminatory decision-making.

In automated policing, electronic and mechanical devices replace the human labour of surveillance, investigation and case preparation. Automation reduces discretion. For example, once video recording has started, the officer wearing BWV loses some control over what events to film, how much to record, and the analysis and reporting of the recorded information. Automation offers the advantages of timeliness, predictability and consistency; it reduces the risk that controls will be circumvented. As with all technologies, there are potential risks, including privacy intrusion, reliance on inaccurate systems and unauthorised access to, changes to and potential loss of data.

Technology is not the only way to reduce police discretion, of course. Tighter rules, closer supervision, targets, quotas, more stringent record-keeping, external surveillance and oversight can all reduce the opportunities for subjective judgments and decision-making. The absence of a machine does not necessarily mean wide discretion, though automation generally does have the effect of reducing discretion by rendering actions visible. On the other hand, automation can be disrupted and returned to manual control by allowing officers discretion about when to use their mental capacity and physical dexterity (manual in a literal sense, as in 'with the hand') to switch the camera on and off. Preventing manual override and the potential for selectivity and susceptibility to human error would require BWV either to be switched on permanently or the on/off function to be fully automated.

BWV connects police surveillant, investigative, analytical, probative and regulatory functions in new ways. However, any decision to activate BWV cameras is currently entirely at officers' discretion. The question of officer discretion is central to how we conceive of automation - if officers can decide when to turn the camera on, is this still within the realm of context-specific decision-making? Or does it represent part of the 'automating' impetus towards consistent law enforcement? Arguments about whether officers should continuously record or have the discretion to decide when to begin filming are at the heart of this issue.

At present, officers in the UK exercise discretion as to when the camera should be turned on. In the UK, citizens have no right not to be filmed. The College of Policing guidelines for the use of BWV state:

'Principle 4: The operational use of body-worn video must be proportionate, legitimate and necessary .... Continuous, non-specific recording is not permitted. Principle 5: Use of body-worn video will be incident-specific. Officers will use common sense and sound judgement when using body-worn video, in support of the principles of best evidence.' (College of Policing, 2014, p. 5) 
This clearly puts the onus on the officer to make a context-specific decision. The guidelines state that BWV can provide useful evidence on incidents occurring during night-time patrols as well as domestic-abuse cases, but its use in stop-and-search encounters expressly cannot be for the purpose of identifying the subject of the stop. Officers are encouraged to make a verbal announcement that the equipment has been activated when they begin to record and should indicate why they are discontinuing recording before concluding.

There is more speculation on the point of discretion in the US, where some operational guidelines specify which law-enforcement encounters must be recorded. These include (1) calls for service and en route to emergency calls, (2) pedestrian stops and stops on grounds of reasonable suspicion, (3) traffic stops, (4) foot and vehicle pursuit, (5) consensual and warrantless searches, (6) execution of search warrants, (7) arrests and detentions, (8) transports and (9) other adversarial encounters (Brennan Centre for Justice, 2016). This encompasses a wide range of police activity and is distinct from the current UK 'incident-specific' approach, which gives greater scope to officer judgment. The ACLU position is that, from an accountability perspective, continuous recording allows the best outcomes, but that this raises privacy issues for the public and for officers, turning BWVs into generalised surveillance tools. The ACLU recommendations also include an evidentiary presumption against an officer who is wearing a body-worn camera but who failed to record an encounter that later gave rise to a complaint. These recommendations are important to consider because, at the moment, there is no incentive to use cameras consistently nor is there a clear understanding of their evidentiary outcomes. The question of discretion is also complicated in other ways: some cameras do not have the battery life to permit continuous recording, and the use of cameras also multiplies the labour and infrastructure costs involved in storing and processing recorded video data.

The ability for officers to choose when to turn recording on and off constrains transparency and accountability. For Taylor (2016, p. 131), '[c]ameras could be considered the equivalent of the police notebook, but only if it is accepted that the pages of the notebook can be rewritten, edited, modified; even torn out entirely'. Taylor argues that 'limiting the discretion of police officers to select when to record is critical [to ensure] greater transparency, fairness and accountability' (Taylor, 2016, p. 131). BWVs represent an intrusion upon a citizen's privacy and can have disproportionate outcomes in a way that CCTV cameras do not - BWVs can listen in on conversations and are attached to the officers who seek out individuals (Miller et al., 2014, p. 11). There is a tension here: on the one hand, BWV is supposed to make the police more accountable by consistently collecting evidence of their interactions with subjects. On the other hand, officer discretion to not record helps to meet subjects' reasonable expectation of privacy in the same way as the discretion not to arrest protects liberty.

\subsection{Discretion, decision-making and discrimination}

Questions of the impact of discretion on police decision-making are particularly important where children and minority groups are concerned. A crucial issue concerns the ways in which innovation in the collection and analysis of police data leads to practices that amplify inequalities of age and ethnicity. This is what Ferguson calls the 'black data' problem (2017, p. 131), which comprises overlapping concerns with data-driven policing, transparency and racial inequality. Racial inequalities in the US (as well as in the UK and elsewhere) have persisted over a long period of time. People from Black and ethnic minority communities are more likely to come into contact with the police (see also Bowling and Phillips, 2002; 2007) and therefore, like other crime data, video images of people of colour are more likely to be captured, stored and potentially used as evidence.

Ferguson argues that data-driven policing 'reifies many of the systemic inequalities of traditional policing' (2017, p. 132). Decisions about the targeting of policing in terms of place is based on data that encode 'prior decisions of a criminal justice system that disproportionately punishes people of color' (Ferguson, 2017, p. 132). Suspect-based targeting also reflects prior arrests, suspected gang associations and so on, which in turn reflects the 'socioeconomic impacts of traditional policing patterns' (Ferguson, 2017, p. 132). These forms of policing carry a large margin of error, can legitimise 
profiling based on race, gender and socio-economic factors, and may produce many false positives (Ferguson, 2017, p. 132). Big Brother Watch, for example, noted that Durham Constabulary used BWVs to gather updated images of 'known villains' during stop-and-searches (2017); and the College of Policing guidelines state that there is no prohibition on taking photographs during stop-and-searches under the Police and Criminal Evidence Act (1984), and therefore the decision as to whether it is proportionate to use BWV in stop-and-searches is at the officer's discretion (Home Office, 2017a).

In R. v. Commissioner of Police for the Metropolis (2009), ${ }^{7}$ it was held that photographs or other recordings by the police do not prima facie contravene police powers, but must be justifiable on a case-by-case basis. This case involved photographing a peaceful protestor in order to identify potential offenders and the photographs were retained for an unreasonable length of time against the request of the protestor. The Court of Appeal held that the taking and retention of photographs pursued legitimate aims (the prevention of disorder or crime and the safeguarding of public safety) but, once it became clear that the individual had not committed an offence, the images had to be deleted. What is unlawful here is not recording an image, but retaining it beyond the point at which there was reason to suppose that the individual had engaged in criminal conduct. Arguably, while this does protect citizens from unjustified long-term surveillance, it also means that a much higher level of discretion is left to the officer in determining which cases are worth recording. It is also unclear how an individual citizen would be able to prove per College of Policing guidelines that the very use of BWV was unjustified. The central tension between privacy and discrimination outcomes and the risks of discretion remain unresolved. These have wider impacts if the footage is linked to other databases with wider information being made immediately available to the officer.

Since it is more likely that people from Black and minority ethnic communities in the UK will be caught on camera, as they are more likely to come into contact with the police (Bowling and Phillips, 2002), there is a greater risk of this footage being mined by various recognition technologies. This is akin to the overrepresentation of Black people in the DNA database; the disproportional representation of minorities in one police database that is then linked to others could have disproportionate effects across the spectrum of evidence collected on citizens by the police. This is because BWV is part of a larger assemblage of surveillance tools, such as CCTV and dashboard cameras, which already capture a disproportionate number of images of individuals who spend a great deal of time on the streets without access to private space (homeless people, young people and people of colour).

BWVs could also be used to compile 'risk information' on individuals and localities, overrepresenting minority neighbourhoods on police databases. Because predictive policing is based on prior arrests and information about suspected gang associations, it is very likely to reproduce and reify the systemic inequalities of traditional policing (Ferguson, 2017, pp. 131-142). Although it is claimed that big data technologies will avoid racially biased effects, this cannot be achieved without confronting the complexities of 'new technologies and old practices' (Ferguson, 2017, p. 142). Discretion here can meld with a policing practice that has traditionally been used to target minority communities, potentially generating discriminatory outcomes. Returning to Ariel et al. (2016), where discretion in turning the camera on and off was permitted, use-of-force rates were 71 percent higher than where discretion was not permitted. They concluded that BWVs can 'reduce police use of force when ... officers' discretion to turn cameras on or off is minimized' (Ariel et al., 2016, p. 454). This is worrying, and runs counter to the stated purpose of introducing BWV technology in the first place.

Reducing discretion can cut both ways and could well have discriminatory outcomes of its own. Mateescu et al. (2016, p. 123) warn that the use of BWV may also change policing more dramatically, expanding low-level arrests to meet quotas, as officers may be more likely to follow procedure when recorded on the job. As Guidou (2012, quoted in Eyssartier and Hamelin, 2013) notes, 'the job of police officers is changing rapidly with a redefinition of work, a redistribution of tasks, and a developing technology, which offers some advantages but hinders the freedom and the autonomy of the

${ }^{7} R$. (on the application of Wood) v. Commissioner of Police for the Metropolis [2009] EWCA Civ 414. 
agents'. In this case, BWV is seen as having a potentially detrimental effect by reducing the scope for discretion through heightened visibility on the job. This points to the risk of automation embedding or reinforcing 'machine bias' produced by pre-existing discriminatory practices (see Angwin et al., 2016). As Ferguson (2017, p. 48) demonstrates, 'disproportionate minority contact with the criminal justice system seeds the algorithms that generate heat-list-inspired predictive models'. Adams and Mastracci (2017) argue that officers should have a wide amount of discretion in deciding what BWVs record because the technology is potentially very intrusive and can represent the state surveillance of people's private lives and homes. On the other hand, 'a camera that can be switched off, or wilfully turned away from a police interaction with an assailant without consequence, cannot increase accountability or reduce poor policing practice' (Taylor, 2016, p. 130).

Either way, given the amount of discretion that is left to officers in the 'incident-driven' approach, BWVs automate the process of surveillance, evidence collection and analysis only when the camera is switched on manually. Where discretion predominates, humans are able to make context-specific decisions that they believe best suit the circumstances. This may be seen as inefficient. However, Hartzog et al. (2015) suggest that inefficiency is an effective safeguard against perfectly enforcing laws that were created with implicit assumptions of leniency and discretion' (p. 1763). In other words, perfect and consistent law enforcement can be the enemy of fairness in criminal justice. These arguments have also been made in the context of road policing, with some officers complaining that automation removes the opportunity to explain to people the dangers of speeding, the gravity of their offence or give them a chance to explain their behaviour (Eyssartier and Hamelin, 2013).

The 'techno-fix' in the field of road policing not only serves to monitor and punish 'risky populations', but is also commonly experienced as unfair and unjust by 'respectable, upstanding members of the community' who break road-traffic laws (Wells, 2008, p. 802). The virtues of automated speed detection, such as consistency, neutrality and impartiality, are not perceived as just when those caught do not accept the legitimacy of the speed restrictions, the placement of detection devices and the denial of 'voice' in proceedings. Wells (2008) argues that such personal factors as 'common sense', discretion and respect are vital to achieving a just experience. These are conditions of human enforcement and interpersonal encounters. They do not apply to human-machine interactions, which can be experienced as 'too impartial, neutral and consistent' (Wells, 2008, p. 814, emphasis in original). Many of the drivers interviewed by Wells demanded that 'all kinds of biases and discrimination be put back into the system' (Wells, 2008, p. 814, emphasis in original). This may not be a justifiable demand because, as Wells (2008, p. 808) points out, unbiased enforcement can be experienced as too fair 'in that it does not discriminate enough for people who are used to discrimination working in their favour'. The fact that 'low visibility' may allow discrimination to persist in policing work has formed part of the push to introduce the technology. Nonetheless, the widespread perception that automatic processes are unfair undercuts one of the stated objectives of BWVs: improving community trust and police accountability.

To the degree that discretion plays a determining role in the use of the technology, BWVs do not entirely replace human behaviour. To the extent that we assume that automating a process involves consistent outcomes and perfectly enforced laws, the BWV camera is a machine embedded in human behaviour and discretion. It forms part of a larger surveillance and investigative apparatus alongside CCTV cameras, automatic licence-plate readers, dashboard cameras, facial recognition, gait recognition, etc. The interpretation of the footage is still heavily dependent on humans. It is, however, a machine that changes human behaviour and automates some, but not all, processes of surveillance, investigation and evidence testing. The risks of prioritising either consistent decisions through automation or context-specific decision-making through discretion are magnified by the potential for 'mission creep', with ramifications throughout the criminal justice process for those caught on BWV footage.

\footnotetext{
${ }^{8}$ The process by which technology introduced for one purpose comes to be used for another is termed as 'mission creep'.
} 


\section{Conclusion}

It is clear that BWV is automating some specific front-line policing tasks. The human labour of close observation, recording suspicious movements and using a notebook and pen to record interviews with suspects and witnesses are being replaced by machines that can do the same jobs - arguably rather better than through manual labour - with little or no human intervention. Other laborious manual tasks such as searching through observational records for known offenders or visual evidence of the actus reus of an offence, or extracting exactly what was said by whom and when, producing factual reports and preparing evidence for court are now being done by machines using AI.

In the near future, some of the basic craft skills of the front-line police officer will become redundant or change significantly. Officers will need new technical skills to operate technical equipment and manage the data and analytics the machines produce. In common with police involved in intelligence management and other 'high policing' tasks (Brodeur, 1983), everyday 'low policing' will become 'knowledge work' (Ericson and Haggerty, 1997). Much of this will be automated and informated. BWV will contribute to shifting the police role towards the automatic accumulation, analysis and transmission of information (Ericson and Haggerty, 1997, p. 128).

There are limits to how far policework can be automated, however. Many traditional craft skills will remain relevant and seem likely to become more visible with the roll-out of BWV. Skills such as engaging calmly and politely with members of the public, using coercive and intrusive powers judiciously, and being fair and effective in the practice of investigative interviewing will remain relevant; indeed, they will become more visible in an environment in which recording and analysis are informated and automated. Changes to crime control are happening at the same time as a whole range of human activity is being automated and the police will have to respond to a more highly mechanised society.

What does the example of BWV tell us about the future use of technology in crime control? First, automation is happening much more swiftly in some realms of policing than in others. Second, the introduction of technology is happening before legislators and society at large have had the chance to reflect on the consequences; the mechanisms required to ensure technology is used with appropriate standards of transparency, fairness and accountability are not yet in place. Third, technology introduced into policing may automate some processes but, in other spheres, it will simply change the nature of human labour. Fourth, despite the automation of some skills, police still retain a high degree of discretion in the operation of this technology and the capacity for manual override creates new problems. Fifth, although we may value context-specific decision-making made by police officers, abuse of discretion will have the capacity to generate disproportionate outcomes across the system through an interlinking of technological databases.

Zuboff s first law of information technology - all that can be automated will be automated reminds us of the importance of regulatory frameworks that put in place effective oversight over the way visual data are collected, used and made transparent to the public. The Surveillance Camera Code of Practice sets out a vision of 'surveillance by consent' in the mould of 'policing by consent' (Home Office, 2013). However, failure to act in accordance with the code does not open up the police to civil or criminal liability. The code merely states that surveillance equipment should only be used where there is a clear and legitimate aim and having identified a pressing need. On these counts, it is unclear whether BWV does have a clear aim, or - since its applications are multiple - what it aims to achieve at any specific moment.

Even once the goals have been clarified, it remains impossible to judge whether BWV is achieving its aims because data are not systematically collected, collated or made public. We lack evidence about the outcomes of using body-worn camera evidence in criminal trials, nor can we track the ramifications of body-worn cameras through the criminal justice system. This is a crucial avenue for further empirical work that can identify the risks of putting in place programmes without understanding their unintended consequences, as well as how evidence collected by cameras is interpreted later in the criminal justice process. We need to be clear about how body cameras operate in everyday police 
work and subsequently in the criminal justice process as well as their effects and unintended consequences. We need to understand more clearly the potential pitfalls of technologies that are on the cusp of being introduced that will automate aspects of evidence collection by front-line officers while being bounded by human decision-making.

This paper explored two key threads: a foreground thread about BWV as a specific technology and a background thread about the more general development of automated policing. The foreground thread concerns the extent of police discretion in the use of BWV. Here, the tension is between more and less discretion. With more discretion, there is, on the face of it, less transparency and less accountability, as well as more opportunity for abusive and discriminatory policing. With less discretion, there is a threat to privacy but, on the face of it, more transparency and accountability. But, because we know so little about the impact of discretion on the practice of 'policing by consent', we do not know which approach is more effective; and, without a general debate about BWV, we do not know which approach would be more acceptable.

The background thread stems from the observation that the use of BWVs is not an isolated example of the automation of policing. As seems clear, the direction of travel is towards more automation. The extensive moves across policing, law enforcement and the criminal justice system towards the utilisation of mechanical devices at the interface between police and public, the assembly of large databases, the use of AI and machine learning, and creation of digital infrastructure all point in the direction of 'technological management' (Brownsword, 2019). These changes seem likely to alter fundamentally the way in which society is regulated (Brownsword, 2019). The implications of these changes become more important when considering the rapid introduction of police robots and drones that use the same mobile video technology, vehicle number-plate- and people-recognition analytics and reporting capabilities described in this paper. The technological capacities of police robots will be much greater than existing technology, including continuous recording by multiple cameras enabling 360-degree vision in low- and no-light conditions, thermal imaging and capacity to store many weeks of video data. The integration of video cameras into police uniforms provides an indication of how police robots will function and offers an opportunity to think about public awareness and perceptions of automated policing and the mechanisms that are required to regulate it.

The implications of the development of automated policing go far beyond the roll-out of BWV and the foreground tensions around changes in the degree of discretion when manual tasks are automated. The gradual automation of core police tasks points to a major research agenda for legal theorists and social scientists focused on questions about the relationship between human beings and machines in policing, law enforcement and criminal justice. There are empirical questions to be asked about how the technology is used in practice and how it is changing, augmenting and replacing human labour: comparative research questions about how this technology is being rolled out in the Global South and the extent to which other parts of the world are responding to law-enforcement technologies; evaluative questions of effectiveness, fairness and cost; legal and regulatory questions about privacy, liability, accountability and control; and normative questions about trust, autonomy and liberty. These are questions that legislators and communities must grapple with as we try to decide on the kind of society we wish to live in and how intrusive and coercive technologies can be harnessed to the common goals of safety and freedom.

Acknowledgements. A version of this paper was presented at the King's Transnational Law Summit, April 2018. The authors are grateful to King's College London for financial support for this project in the form of a King's Undergraduate Research Fellowship. We wish to thank Karen Yeung for her contribution to this paper in stimulating the idea for this project in the first instance and for early discussions that found their way into our thinking. The paper has benefited from comments from Roger Brownsword, Fares Djenandji, Alon Harel, Amber Marks, Johannes Sahmland Bowling and Charmian Werren.

\section{References}

Adams I and Mastracci S (2017) Visibility is a trap: the ethics of police body-worn cameras and control. Administrative Theory and Praxis 39, 313-328. 
Aguayo R et al. (2017) Detecting footchases from police body-worn video, SIAM Undergraduate Research Online, 31 March. Available at https://www.semanticscholar.org/paper/DETECTING-FOOT-CHASES-FROM-POLICE-BODY-WORN-VIDEOAguayo-Camacho/c838463818a4b0297111950e4550bf751ed2e107 (accessed 15 March 2019).

Allen S et al. (2017) Change-point detection methods for body worn video. SIAM Undergraduate Research Online, 1 February. Available at https://doi.org/10.1137/16S015164 (accessed 20 February 2019).

American Civil Liberties Union (2002) What's Wrong With Public Video Surveillance? New York: ACLU. Available at https://www.aclu.org/other/whats-wrong-public-video-surveillance (accessed 20 February 2019).

Angwin J et al. (2016) Machine bias, Pro Publica, 23 May. Available at https://www.propublica.org/article/machine-bias-riskassessments-in-criminal-sentencing (accessed 20 February 2019).

Arendt H (1998) The Human Condition, 2nd revised edn. Chicago: University of Chicago Press.

Ariel B (2016) Police body cameras in large police departments. Journal of Criminal Law and Criminology 106, 729-768.

Ariel B et al. (2016) 'Contagious accountability': a global multisite randomized controlled trial on the effect of police bodyworn cameras on citizen's complaints against the police. Criminal Justice and Behaviour 44, 293-316.

Ariel B, Farrar W and Sutherland A (2014) The effect of police body-worn cameras on use of force and citizens' complaints against the police: a randomized controlled trial. Journal of Quantitative Criminology 31, 509-535.

Balko R (2016) 80 Percent of Chicago PD dash-cam videos are missing audio due to 'officer error' or 'intentional destruction', The Washington Post, 29 January. Available at https:/www.washingtonpost.com/news/the-watch/wp/2016/01/29/80 percent-of-chicago-pd-dash-cam-videos-are-missing-audio-due-to-officer-error-or-intentional-destruction/?noredirect= on\&utm_term $=.51 \mathrm{clbc67e} 464$ (accessed 20 February 2019).

BBC News (2014) Leicestershire Police trial facial recognition software, 15 July. Available at https://www.bbc.com/news/ukengland-leicestershire-28307938 (accessed 20 February 2019).

Big Brother Watch (2017) Smile, you're on body worn camera, Part II - Police. London: Big Brother Watch. Available at https://bigbrotherwatch.org.uk/wp-content/uploads/2017/08/Smile-Youre-on-Body-Worn-Camera-Part-II-Police-II.pdf (accessed 19 February 2019).

Bowling B and Phillips C (2002) Racism, Crime and Justice. London: Pearson.

Bowling B and Phillips C (2007) Disproportionate and discriminatory: reviewing the evidence on police stop and search. Modern Law Review 70, 936-961.

Bowling B, Marks A and Murphy C (2008) Crime control technologies: towards an analytical framework and research agenda. In Brownsword R and Yeung K (eds), Regulating Technologies. Oxford: Hart Publishing, pp. 53-78.

Bowling B, Reiner R and Sheptycki J (2019) The Politics of the Police, 5th edn. Oxford: Oxford University Press.

Brennan Center for Justice (2016) Police Body Camera Policies: Recording Circumstances. New York: Brennan Center for Justice. Available at https://www.brennancenter.org/analysis/police-body-camera-policies-recording-circumstances (accessed 20 February 2019).

Brodeur JP (1983) High and low policing: remarks about the policing of political activities. Social Problems 30, 507-520.

Brown GR (2016) The blue line on thin ice: police use of force modifications in the era of cameraphones and Youtube. British Journal of Criminology 56, 293-312.

Brownsword R (2019) Law, Technology, and Society - Re-imagining the Regulatory Environment. Abingdon: Routledge.

College of Policing (2014) Body-worn Video. Coventry: College of Policing. Available at http://library.college.police.uk/docs/ college-of-policing/Body-worn-video-guidance-2014.pdf (accessed 19 February 2019).

Corso J et al. (2015) Video Analysis for Body-worn Cameras in Law Enforcement: A White Paper Prepared for the Computing Community Consortium Committee of the Computing Research Association. Washington, DC: Computing Community Consortium. Available at https://arxiv.org/ftp/arxiv/papers/1604/1604.03130.pdf (accessed 19 February 2019).

Edwards L (2005) Switching off the surveillance society? Legal regulation of CCTV in the UK. In Prins C et al. (eds), Reasonable Expectations of Privacy: The Privacy Network. The Hague: Asser Press.

Ellison M and Adams L (2017) Issues with police body-worn camera system revealed, BBC, 28 April. Available at https:// www.bbc.com/news/uk-scotland-39730665 (accessed 19 February 2019).

Ericson R and Haggerty K (1997) Policing the Risk Society. Oxford: Oxford University Press.

Eyssartier C and Hamelin F (2013) Police officers and professional road users: the impact of automatic speed cameras on the social representation of the job. Revue internationale de psychologie sociale 26, 207-229.

Ferguson AG (2017) The Rise of Big Data Policing: Surveillance, Race and the Future of Law Enforcement. New York: New York University Press.

Gates K (2016) The work of wearing cameras: body-worn devices and police media labour. In Maxwell R (ed.), Routledge Companion to Media and Labour. New York: Routledge, pp. 20-28.

Goldsmith AJ (2010) Policing's new visibility. British Journal of Criminology 50, 914-934.

Goldstein J (1960) Police discretion not to invoke the criminal process: low-visibility decisions in the administration of justice. Faculty Scholarship Series, 2426. Available at https://digitalcommons.law.yale.edu/fss_papers/2426 (accessed 20 February 2019).

Goodall M (2007) Guidance for the Police Use of Body-worn Video Devices. London: Home Office, Police and Crime Standards Directorate. Available at http://library.college.police.uk/docs/homeoffice/guidance-body-worn-devices.pdf (accessed 19 February 2019). 
Goodison S, Davis R and Wilson T (2018) Costs and Benefits of Body-worn Camera Deployment. Washington, DC: Police Executive Research Forum. Available at https://www.policeforum.org/assets/BWCCostBenefit.pdf (accessed 19 February 2019).

Goold BJ (2002) Privacy rights and public spaces: CCTV and the problem of the 'unobservable observer'. Criminal Justice Ethics 21, 21-27.

Goold BJ (2004) CCTV and Policing: Public Area Surveillance and Police Practice in Britain. Oxford: Oxford University Press.

Grossmith L et al. (2015) Police, Camera, Evidence: London's Cluster Randomised Controlled Trial of Body Worn Video. London: College of Policing. Available at https://whatworks.college.police.uk/Research/Documents/Police_Camera_ Evidence.pdf (accessed 19 February 2019).

Guidou N (2012) Malaise dans la police: Perte d'identité, violences au quotidien, politique du chiffre: une profession au bord de l'explosion [Discomfort in the Police: Loss of Identity, Daily Violence, Number Politics: A Profession on the Verge of Explosion]. Paris: Eyrolls.

Hartzog W et al. (2015) Inefficiently automated law enforcement. Michigan State Law Review 2015, 1763-1796.

Hogan-Howe B (2015) 2020 Vision: Public Safety in a Global City, speech at Royal Society of Arts, 12 March 2015.

Home Office (2013) Surveillance Camera Code of Practice. London: Home Office.

Home Office (2017a) Guidance for the Police Use of Body-worn Video Devices. London: Home Office, Police Crime and Standards Directorate.

Home Office (2017b) Home Office Consults on Using Body-worn Video for Police Interviews. London: Home Office. Available at https://www.gov.uk/government/news/home-office-consults-on-using-body-worn-video-for-police-interviews (accessed 19 February 2019).

House of Commons (2015) Body-worn Video in UK Policing. London: Houses of Parliament, Office of Science and Technology.

Hung V, Babin S and Coberly J (2016) A Market Survey on Body-worn Camera Technologies, prepared for the Department of Justice's National Institute of Justice by the John Hopkins University Applied Physics Laboratory. Available at https:// www.ncjrs.gov/pdffiles1/nij/grants/250381.pdf (accessed 31 December 2018).

Hymas C (2018) Traditional police notebook gives way to body-worn video for police interviews of suspects and witnesses, Daily Telegraph, 30 November.

Independent Police Complaints Commission (IPCC) (2016) IPCC Position Statement on Body Worn Video. London: Independent Police Complaints Commission. Available at https://www.policeconduct.gov.uk/sites/default/files/Documents/ Who-we-are/Our-Policies/IPCC_position_statement_on_body_worn_video.pdf (accessed 19 February 2019).

Jackson J (2008) Police and prosecutors after PACE: the road from case construction to case disposal. In Cape E and Young R (eds), Regulating Policing: The Police and Criminal Evidence Act 1984, Past, Present and Future. Oxford: Hart.

Joh E (2018a) Automated policing. Ohio State Journal of Criminal Law 15, 559-563.

Joh E (2018b) Policing the smart city. International Journal of Law in Context published online 17 June 2018, https://papers. ssrn.com/sol3/papers.cfm?abstract_id=3189089 (accessed 20 February 2019).

Katz CM et al. (2014) Evaluating the Impact of Officer Worn Body Cameras in the Phoenix Police Department. Phoenix, AZ: Centre for Violence Prevention and Community Safety.

Khan MQ (2015) Police Technophobia. Saarbrucken: Lambert Academic Publishing.

Kinsella C and McGarry J (2011) Computer says no: technology and accountability in policing traffic stops. Crime, Law and Social Change 55, 167-184.

Li S (2014) The big picture: how do police body cameras work?, The Atlantic, 25 August. Available at https://www.theatlantic. com/national/archive/2014/08/how-do-police-body-camera-work/378940/ (accessed 19 February 2019).

Magee T (2016) Met Police to store body camera data indefinitely in Microsoft cloud, Techworld, 1 December. Available at https://www.techworld.com/security/met-police-picks-microsoft-cloud-store-body-camera-video-evidence-indefinitely3651105/ (accessed 2 June 2018).

Magnet S and Gates K (2013) The New Media of Surveillance. New York: Routledge.

Marks A, Bowling B and Keenan C (2017) Automatic justice? Technology, crime and social control. In Brownsword R, Scotford E and Yeung K (eds), The Oxford Handbook of Law, Regulation and Technology. Oxford: Oxford University Press.

Marx GT (2002) What's new about the 'new surveillance'? Classifying for change and continuity. Surveillance and Society 1, $8-29$.

Marx K (1863/1978) Theories of Surplus Value, Vol. 1. Moscow: Progress Publishers.

Mateescu A, Rosenblat A and Boyd D (2016) Dreams of accountability, guaranteed surveillance: the promises and costs of body-worn cameras. Surveillance and Society 14, 122-127.

Metropolitan Police (2016) Body Worn Video (BWV) Policy Statement. London: Metropolitan Police. Available at https:// www.met.police.uk/SysSiteAssets/foi-media/metropolitan-police/policies/bwv_policy_statement_february2017.pdf (accessed 15 March 2019).

Miller L, Toliver J and Police Executive Research Forum (2014) Implementing a Body-worn Camera Program: Recommendations and Lessons Learned. Washington, DC: Office of Community Oriented Policing Services. 
McGarry J (2011) Named, shamed, and defamed by the police. Policing 5, 219-227.

Motor Insurers' Bureau (2010) Welcome to the Motor Insurers' Bureau. London: Motor Insurers' Bureau. Available at www. mib.org.uk/ (accessed 20 November 2018).

Norris C and Armstrong G (1999) CCTV and the social structuring of surveillance. Crime Prevention Studies 10, $157-178$.

Owens C, Mann D and McKenna R (2014) The Essex Body Worn Video Trial: The Impact of Body Worn Video on Criminal Justice Outcomes of Domestic Abuse Incidents. London: College of Policing.

Palmer D (2016) The mythical properties of police body-worn cameras: a solution in search of a problem. Surveillance and Society 14, 138-144.

Pasternack A (2017a) Police body cameras will do more than just record you, FastCompany, 3 March. Available at https:// www.fastcompany.com/3061935/police-body-cameras-livestreaming-face-recognition-and-ai (accessed 15 July 2018).

Pasternack A (2017b) Taser acquires a computer vision startup to bring AI to police body cameras, FastCompany, 2 September. Available at https://www.fastcompany.com/4030358/taser-acquires-computer-vision-startup-dextro-to-bringai-to-police-body-cameras (accessed 15 July 2018).

Peachey P (2016) How the police's body-worn camera technology is changing the justice system, The Independent, 1 March. Available at https://www.independent.co.uk/news/uk/crime/how-the-polices-body-worn-camera-technology-is-changingthe-justice-system-a6905691.html (accessed 12 May 2018).

Police Scotland (2015) Body Worn Video: Aberdeen City Division Procedure. Aberdeen: Police Scotland. Available at https:/ www.whatdotheyknow.com/request/235722/response/586342/attach/5/BodyWornVideoV9\%20PSoS\%20SOP.pdf (accessed 2 July 2018).

PRNewswire (2017) COBAN technologies and digital barriers partner on live facial recognition and video streaming. Available at https://www.prnewswire.com/news-releases/coban-technologies-and-digital-barriers-partner-on-live-facialrecognition-and-video-streaming-300542758.html (accessed 31 December 2018).

Rowe M, Pearson G and Turner E (2017) Body-worn cameras and the law of unintended consequences: some questions arising from emergent practices. Policing: A Journal of Policy and Practice 12, 83-90.

RT News (2013) Chicago police start using facial-recognition software to arrest suspects, RT News, 15 July. Available at https://www.rt.com/usa/chicago-police-cctv-surveillance-135 (accessed 15 December 2018).

Rule J (1973) Private Lives and Public Surveillance. London: Allen Lane.

Sanburn J and Sifferlin A (2014) Seattle police to use facial recognition software, Time, 14 March. Available at http://time. com/25605/seattle-police-to-use-facial-recognition-software (accessed 12 November 2018).

Sanders C and Sheptycki J (2017) Policing, crime and 'big data'; towards a critique of the moral economy of stochastic governance. Crime, Law and Social Change 68, 1-15.

Sandhu A (2016) Camera-friendly policing: how the police respond to cameras and photographers. Surveillance and Society 14, 78-89.

Skolnick J (2011) Justice Without Trial: Law Enforcement in Democratic Society. New Orleans, LA: Quid Pro Books.

Smykla O et al. (2015) Police body-worn cameras: perceptions of law enforcement leadership. American Journal of Criminal Justice 41, 424-443.

Snow A (2017) Automated Road Traffic Enforcement: Regulation, Governance and Use. London: Royal Automobile Club Foundation.

Stanley J (2015) Police Body-mounted Cameras: With Right Policies in Place, A Win for All. New York: ACLU. Available at https://www.aclu.org/other/police-body-mounted-cameras-right-policies-place-win-all?redirect=police-body-mountedcameras-right-policies-place-win-all (accessed 31 December 2018).

Stedmon A (2011) The camera never lies, or does it? The dangers of taking CCTV surveillance at face value. Surveillance and Society 8, 527-534.

Surrey Police (2017) Body worn video (BWV) procedure, 30 October 2017. Available at https://surrey.police.uk/policies-andprocedures/body-worn-video-bwv-procedure/ (accessed 31 December 2018).

Taylor E (2016) Lights, camera, redaction... police body-worn cameras: autonomy, discretion and accountability. Surveillance and Society 14, 128-132.

Taylor E and Gill M (2014) CCTV: reflections on its use, abuse, and effectiveness. In Gill M (ed.), The Handbook of Security. London: Palgrave Macmillan.

Telegraph, The (2017) Armed Met Police officers to wear head-mounted cameras for first time, The Telegraph, 14 August. Available at https://www.telegraph.co.uk/news/2017/08/14/armed-met-police-officers-wear-head-mounted-cameras-firsttime/ (accessed 5 December 2018).

Tubb G (2015) Security fears over police body-cameras, Sky News, 20 August. Available at https://news.sky.com/story/security-fears-over-police-body-cameras-10348763 (accessed 11 November 2018).

United States Department of Justice (2015) Justice Department Awards over \$23 Million in Funding for Body Worn Camera Pilot Program to Support Law Enforcement Agencies in 32 States. Washington, DC: Department of Justice. Available at https://www.justice.gov/opa/pr/justice-department-awards-over-23-million-funding-body-worn-camera-pilot-programsupport-law (accessed 5 January 2019). 
Wells H (2008) The techno-fix versus the fair cop: procedural (in)justice and automated speed limit enforcement. British Journal of Criminology 48, 798-817.

Williams T et al. (2016) Police body cameras - what do you see?, The New York Times, 1 April. Available at https://www. nytimes.com/interactive/2016/04/01/us/police-bodycam-video.html (accessed 4 January 2018).

Willis C (1984) The Tape Recording of Police Interviews with Suspects: An Interim Report. London: HMSO.

Zuboff S (1988) In the Age of the Smart Machine: The Future of Work and Power. New York: Basic Books.

Zuboff S (2001) Automate/informate: the two faces of intelligent technology. Organizational Dynamic 14, 5-18.

Zuboff S (2013) Be the friction: our response to the New Lords of the Ring, Frankfurter Allgemeine Zeitung 25 published online 25 June 2013, http://www.faz.net/aktuell/feuilleton/the-surveillance-paradigm-be-the-friction-our-response-tothe-new-lords-of-the-ring-12241996.html (accessed 20 February 2019).

Cite this article: Bowling B, Iyer S (2019). Automated policing: the case of body-worn video. International Journal of Law in Context 15, 140-161. https://doi.org/10.1017/S1744552319000089 